\title{
Some Forms of Stylistic Condensation in Newspaper English
}

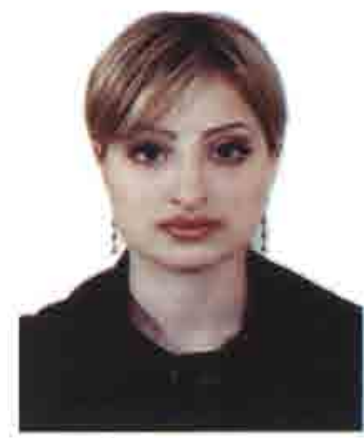

Annu beghyan

W ach discourse type (register, functional style) of Modern English has a system of characteristic linguostylistic features and regularities of functioning of linguistic units. Each style chooses from the neutral and stylistically colored word stock of the language linguistic elements necessary for the formation of its own system and alpable of realizing its communicative goal, i.e. each style represents a correlated system of language units which is directed to the realization of a certain function which the ianguage has in the given sphere of communication. The peculiarities of each speech type derive from this function. In Newspaper English this main and most important function is

to render information.

In other words, press is conceived to provide news to public and basically serves the purpose of informing/instructing the reader and evaluating developments taking place in the society. It also seeks to influence public opinion on political and other matters. To carry out its main and secondary communicative goals, i.e. to realize its informative, evaluative, attractive (to attract the reader's attention and hold it for a certain time), persuasive functions, various linguistic and stylistic devices (special vocabulary and constructions, stereotyped expressions, metaphors, etc) are used.

The traditional newspaper language is much the language of its headlines. This is the reason why many linguists call this speech variety Headline English. It is a language that only gradually, reluctantly is being replaced by a more personal, stylized language aimed at the literate members of pervasive audience. The traditional news story is a form of specific abbreviated and contracted style. Newspaper writing is always shorter and tighter. Always there are words that can be eliminated and ideas that can be condensed.

Thus, one of the most important style-forming peculiarities of Newspaper English is stylistic condensation expressed in linguistic units which are as brief as possible but in no way have a negative impact on the exactness and expressivity of the rendered information.

Stylistic condensation is first of all expressed in specially selected lexical units which are simple, clear, precise and economical. By writing concisely and using condensed forms, reporters try to present as much information to readers as possible. Readers themselves like to get their information in a hurry and do not want to wade through something that looks awesomely long. Brevity also helps readers to catch quickly the main ideas conveyed by each story and there is no need to spend time reading 
long words. The words that are repetitious or state the obvious are largely avoided. It is customary to use active verbs and strong nouns. The newspaper sentence becomes more concise, interesting and informative when a more specific and descriptive verb or noun is used.

In the sentences below from the British daily newspaper "The Times" (issues of July 2 and 23, 2005), the words alert, gatge, key, perceive, tackle, vent, echo substitute the words and word combinations watchfulness, estimation (standard measure), essential, become aware of, deal with, express (provide an outlet for), repeat and are more likely to be used in general literary English language. Changing a single word - the verb or the noun - also changes the sentence's impact and meaning.

The present state of maximum alert is likely to last for weeks.

The gauge came in at 49.6 in June, higher than the previous month's 47 but the third month's below 50, implying that manufacturing activity has been in sustained improvement in this key factor for living standards.

The report also said that the government did not perceive any threat to national security:

Britain is coming under fresh international pressure to put its "own house in order" by tackling the radical clerics and dissident Islamic groups of "Londonistan".

His remarks echoed those of President Musharraf of Pakistan, who vented his exasperation this week over claims that London bombings had been inspired by terror groups in his country.

Thus, forming an appropriate newspaper style means using general, usually shorter lexical units for the specific. The actions can be expressed fluently by only a verb denoting this or that action or situation and a noun which is both descriptive and informative. Weaker, non-descriptive verbs, especially such auxiliaries as is, are, was, were should be avoided. Strong, active verbs as those in the above examples are most colorful, interesting and dramatic.

The omission or elimination of certain useless and unnecessary words or word combinations is considered another form of stylistic condensation conditioning a fluent newspaper style. Using two or more words when only one is necessary is a waste of time and space. Adjectives and adverbs are largely avoided since they tend to be less forceful and less informative. Moreover, they are usually opinionated as compared with verbs and nouns, and are often redundant. This means that the vague qualifiers such as young and old, big and little, early and late, high and low, fast and slow should be avoided. Other vague qualifiers include: rather, very, much, quickly, awhile, and a lot. Labels expressing a personal opinion and loaded words such as chauvinist, demagogue, extremist, racist, segregationist, zealot and the like are also very often excluded. There are some conjunctions and adverbs which are almost unnecessary for the style: that, then, currently, now, presently and so on. In the two examples below from "The Times" (July 2, 2005) and the "Daily Mai" (September 5, 2006) the meanings of the words stand, continue and labour are somehow vague at first sight as the word combination 
in line, the words life or living and the word combination party member are deliberately omitted. Reading the article from the beginning or the sentences up to the end makes it clear that in the first example the employees who are shareholders of the "Nats" company are waiting in line to receive their dividends. In the second example the Japanese scientist is sure that old people would continue to lead a normal life if they use the biotic suit created specially for them. The personified labour turns out to be a member or a representative of the Labour party declaring they could leave Afghanistan without a shot fired.

Employees own about 5 per cent of Nats and stand [in line] to receive between 10 and 50 pounds each, depending on how long they have been employed by the organization.

The professor says [that] people would not notice the aches and pains of old age, and would continue [life or living] as normal.

Labour [ party member] said we could be out of Afghanistan without a shot being fired.

The excessive use of the passive is a most typical characteristic of newspaper style. The examples below from the British "The Daily Mail" (September 5, 2006) demonstrate clearly that the passive constructions is another form of stylistic condensation. The full passive becomes even more condensed when used in a headline.

Successful womb transplants could be carried out within two-three years, according to a leading British surgeon.

A breed of expert chemists is to be given the power to treat patients with illnesses such as Parkinson's and heart disease.

But since her birth. Suri has been kept firmly under wraps, only being introduced to a few select family members and a handful of the couple's celebrity friends.

As the poor chap grew ever more sick, he was bumped up the waiting list.

Another soldier killed by suicide attack

Dardevil Steve Irvin killed as heart is pierced by the barb from a giant stingray'

Liz Tailor cowered in a locked room

Shopkeeper is stabbed to death

When stories are well-written, simplicity makes them clearer and easy to comprehend the information. Well-written stories contain no distracting clutter, but emphasize the most important facts and report those facts in a clear and forceful manner. Another reason for the tendency of Newspaper English to stylistic condensation (using short words, constructions, sentences, paragraphs, omitting certain lexical units) is that newspapers are printed in small type, with narrow columns, on cheap paper. So the material is divided into bite-sized chunks that are easy to read.

There are many forms of wordiness and waste, some of which are unnecessary repetition of words especially in longer passages that involve several sentences. There is 
rarely any need to repeat the same fact two or more times in a single sentence or story. This mainly happens when writers introduce a topic, and then present some specific information about it. Sentences that appear near the end of a paragraph should not repeat facts implied or mentioned earlier. In most cases, however, only the more specific information is needed and it should be introduced precisely. Double meanings are more difficult to detect. One sentence must intend to say one thing or express one idea otherwise the sentence can be misunderstood or interpreted differently. This means short sentences and short paragraphs - typical forms of a condensed style - are applied widely in Newspaper English. Very long and embarrassing sentences are divided into shorter units that are easier to read and understand. Accordingly, information is taken from a sentence with an average of 15-20 words.

The subject-verb-object construction is the sample of newspaper writing. The construction has an internal imperative: it directs towards writing simple sentences, which are sentences with one main clause. This construction is functional since it is the most condensed and direct way of answering the two informative newspaper questions of what happened in society and who was involved.

He has given his party a green makeover. David Cameron is doing the same to his family home. The basement will have light wells front and back. Seven builders are attempting to complete the job. The design also incorporates a tub to recycle rainwater:

All the above sentences from the same article from "The Daily Mail" (September 5,2006 ) begin with the subject, are closely followed by an active verb and the object of the verb. Deviations from such style are possible only when some other elements of a news story is to be emphasized. Generally, paragraphs that begin with long, qualifying clauses and phrases, lack the clarity of simpler, more direct sentences. Long introductory sentences usually bury the news amid less significant details.

Getting to the point of the news in a hurry is also a marker of a condensed form and style. Traditionally this is done in the first two or three paragraphs, known as the "lead" in Newspaper English. Even in stylized stories, where some scene or telling an anecdote is set, the point should be established on, at least by the fifth or sixth paragraph.

Newspaper writing is a concise writing. Accomplished and effective newspaper communication demands clear and accurate selection and arrangement of condensed linguistic units thus making stylistic condensation a basic style-forming peculiarity of Newspaper English.

\section{References:}

1. Alexandrova, O.V., Ter-Minasova, S.G. (1987) English Syntax: Collocation, Colligation and Discourse. Moscow: Moscow University Press.

2. Anderson, R. (1994) Steps and Hints to Get You on the Right Road to Public 
Writing. Chicago: Chicago University Press.

3. Lambeth, E.B., Meyer, P.E. (2000) Assessing Public Journalism. Missouri: Missouri University Press.

4. Mencher, M. (1996) News Reporting and Writing. Columbia: Columbia University Press.

5. The Survey of English Usage. http:www.ucl.ac.uk/english-usage

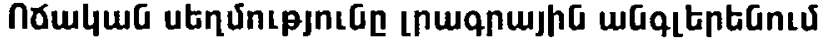

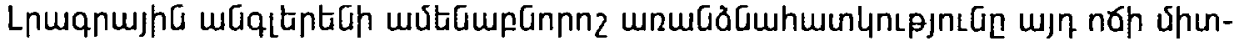

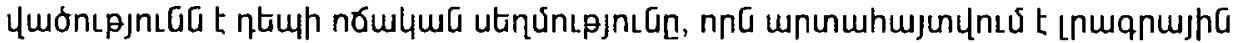

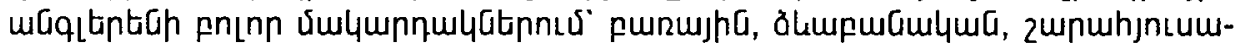

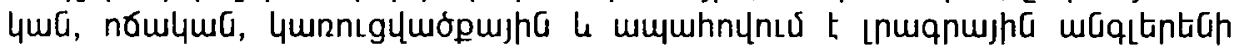

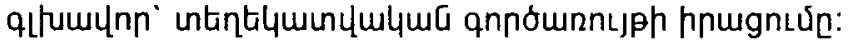

